\title{
Unembedded Definite Descriptions and Relevance
}

\author{
Robert J. Stainton \\ Carleton University
}

\begin{abstract}
Definite descriptions (e.g. 'The king of France in 1997', 'The teacher of Aristotle') do not stand for particulars. Or so I will assume. The semantic alternative has seemed to be that descriptions only have meaning within sentences: i.e., that their semantic contribution is given syncategorimatically. This doesn't seem right, however, because descriptions can be used and understood outside the context of any sentence. Nor is this use simply a matter of "ellipsis." Since descriptions do not denote particulars, but seem to have a meaning in isolation, I propose that they be assigned generalized quantifiers as denotations - i.e. a kind of function, from sets/properties to propositions. I then defend the pragmatic plausibility of this proposal, using Relevance Theory. Specifically, I argue that, even taken as standing for generalized quantifiers, descriptions could still be used and understood in interpersonal communication.
\end{abstract}

\section{Introduction: Real and Apparent Singular Terms ${ }^{1}$}

In the last two decades there has been a salutary move, among those working on the semantics of singular terms, towards direct reference theories. Putting it roughly, simply to fix ideas:

(1) The Hypothesis of Direct Reference: A true singular term merely and simply stands for its bearer. 
To borrow a happy phrase from Ruth Barcan Marcus, according to (1) real singular terms are just tags. As such, they have no connotation hence what they contribute to propositions expressed by full sentences can only be the individual referred to. (This, it is said, contrasts sharply with the semantics of singular terms in the Fregean tradition: For Frege and his followers, singular terms have senses, and it is the sense of a term which the term contributes to the meaning of full sentences. ${ }^{2}$ )

On the whole, (1) is attractive and plausible; in what follows, I'll assume it. Next step: Russell $(1905,1919)$ noted a possible ugly consequence of adopting a direct reference theory. He held, at least post 1905 , that philosophers ought not countenance unreal entities: things which subsist, but fail to exist. For instance, according to this ontological doctrine, one ought not say that the king of France in 1997 is non-existent, but subsists; nor that unicorns, though unreal, subsist. I concur. In spades. A problem arises, however, when one attempts to combine this thesis with (1). For, applying the semantic doctrine, it might seem that 'the king of France in 1997' would of necessity stand for that particular which is its bearer; but, if so, this particular must be. And this conclusion offends Russell's ontological doctrine.

One way out of this dilemma, seen clearly by Russell, is to deny that 'the king of France' functions as a real singular term: It may look like a singular term, but appearances are deceptive. ${ }^{3}$ Granting this, one can simultaneously say that real singular terms merely and simply stand for particulars, but that 'the king of France' does not stand for a particular - because it isn't really a singular term. In which case, there is no need for an individual to which 'the king of France' will refer. (Russell universalizes this view, so that along with obviously non-denoting definite descriptions (e.g. 'the king of France', 'the largest prime'), definite descriptions in general - expressions of the form 'The $F^{\prime}$ - are not singular terms. See Russell 1905, Sainsbury 1979, and Neale 1990 for discussion of the rationale.)

This leaves a nagging question: How do definite descriptions actually work, if they are not true singular terms? The Russellian reply, in a word, is that descriptions should be treated quantificationally. Here is Russell's view, in anachronistic and highly distilled form.

(2) Russellian Theory of Descriptions: A sentence ${ }^{\lceil}$The $F$ is $G^{\top}$ is equivalent to ${ }^{\lceil}$There is exactly one $F$ and every $F$ is $G$.

Everything seems to be going swimmingly. The semantics for singular terms is breathtakingly simple: they merely and simply refer to their bearers. And yet, by distinguishing "real" singular terms and descriptions (where "non-denoting names" become "disguised descriptions"), this semantics need not commit the theorist to unreal particulars. ${ }^{4}$ A question remains, however: can this semantics for definite descriptions be made pragmatically plausible? In particular, is it consistent with known facts about interpersonal communication? That is the central issue of the present paper. 


\section{The Problem: Unembedded Definite Descriptions}

The path I have been tracing is painfully familiar. I want now to introduce a new wrinkle: a small but important worry, deriving from interpersonal communication, for this Russellinspired approach of combining (1) and (2). As Salmon and Soames (1988: 3) note: "According to Russell... sentences containing descriptions are convenient abbreviations for more complex sentences lacking them." I pause to emphasize: Sentences which contain descriptions get translated into sentences which do not. About descriptions outside sentences, (2) says nothing whatever - as Russell himself notes. Given this, Russell's theory as it stands can (at best) capture the communicative contribution of descriptions as they occur in sentences. This wouldn't be a problem, but for the fact that descriptions can be used and understood in isolation.

Let me introduce some data. ${ }^{5}$ Suppose I'm at a linguistics meeting, talking with Andy Brook. There are some empty seats around a table. I point at one and say, 'The editor of Natural Language Semantics'; I then indicate another empty seat and say, 'The editor of Pragmatics and Cognition'. Upon hearing these words, Andy understands what I meant: that the unoccupied seats are reserved for the editor of Natural Language Semantics, and for the editor of Pragmatics and Cognition. Another detail. The seats I pointed to are actually reserved for Emmon Bach and M.A.K. Halliday; and, as a matter of fact, they are not the editors of these journals. Moreover I, the speaker, am aware of this - I'm simply playing a joke on poor Andy. I want to stress two things about this imagined situation. Point one: Since the seat I indicated first is not reserved for the editor of Natural Language Semantics, and since the second seat does not pertain to the editor of Pragmatics and Cognition, I spoke falsely in uttering (3a) and (3b). I made a false statement.

\section{(3) (a) The editor of Natural Language Semantics \\ (b) The editor of Pragmatics and Cognition}

Point two: What I uttered, in the described situation, were two definite descriptions. Neither time did I utter a sentence.

You might be tempted to say: "This isn't really a use of an unembedded definite description. Rather, it's a use of an elliptical sentence - in particular, an elliptical sentence which contains a description." But, as I've argued elsewhere and at length (1995, 1997a,b, and forthcoming), the phenomenon at hand does not count as ellipsis - at least not in any sense that would rescue (2). Unless one means to include under "ellipsis" things like the use of non-sentences (including plain old descriptions) to communicate complete thoughts, this isn't ellipsis: there is no deletion of syntactic material here, no phonological null elements, etc. What occurs, instead, is that information gets communicated without being encoded. In any case, in what follows, I will take for granted that it is not just sentences (elliptical or otherwise), but also ordinary descriptive phrases, that can be used communicatively. (In fact, words and phrases of many kinds can be so used. See Barton 1990 for an overview. My aim in this paper is simply to explore one special, and especially controversial, case.) 
Russell's theory - as he himself formulated it, and as paraphrased in (2) - at best says nothing whatever about the unembedded use of (3), and related cases; at worst, it says that a meaningful utterance of (3) on its own is impossible. On the other hand, given the semantic and ontological advantages of direct-reference-plus-(2), there are solid reasons for holding onto something like (2). What's needed, then, is a variation on Russell's theme one which maintains the spirit of his proposal, while account for the communication of propositions using mere descriptions. In which case, a fix is called for. Here it is, in a nutshell: Definite descriptions used communicatively, whether within a sentence or unembedded, correspond to generalized quantifiers: functions from sets to propositions. (More on this shortly.)

Before continuing to explore this positive proposal about what definite descriptions mean, I want to warn against a misunderstanding. My aim is not to criticize Russell, or his philosophy. When I speak of Russell's theory, and its inadequacies with respect to nonsentential speech, I am making a claim about a contemporary proposal in semantics, and about their pragmatic plausibility - I am not making claims about Russell's views, or the philosophy behind it. Whether Russell should have been concerned about unembedded descriptions I do not know.

\section{The Pragmatics of Unembedded Descriptions}

Allow me to review a little, before going on. I've been discussing what definite descriptions mean. Within a direct reference theory - the approach I'm assuming - you could treat them as denoting particulars; but then, assuming you don't want to countenance unreal entities, you will have trouble with non-denoting descriptions, like 'The king of France in 1997'. The other alternative, pursued by Russell $(1905,1911,1919)$, is to treat descriptions quantificationally.

Here again, there are two options. Following Russell exactly, you can give the semantics for descriptions (and other quantifiers) syncategorimatically, in such a way that sentences containing descriptions are translated into description-free sentences. The other alternative is to treat descriptions as corresponding to generalized quantifiers. Thus instead of specifying the meaning of descriptions in terms of sentences, à la (2), their meaning should be specified as in (5). This is the better option, in my view, because descriptions can be used in isolation - that is, not within any sentence.

(2) Russell's Formulation of the Theory of Descriptions: A sentence ${ }^{\lceil}$The $F$ is $G^{\top}$ is

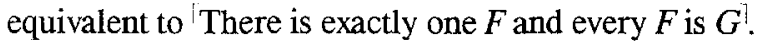

(5) Revised Formulation of the Theory of Descriptions: An expression ${ }^{1}$ The $F^{i}$ corresponds to the function $f$ from sets $G$ to propositions such that $f(G)$ is a true proposition iff there is exactly one $F$ and every $F$ is $G$. 
So much for review. On to a partial defense of (5). A hypothesis about the semantics of an expression must, at the very least, be consistent with facts about how utterances of that expression are typically understood. I'll suppose it uncontroversial that unembedded definite descriptions, when used in context, are often understood as communicating quantified propositions. But, if treating descriptions as corresponding to generalized quantifiers is on the right track, this is not what unembedded descriptions mean: Semantically speaking, an unembedded definite description corresponds, by hypothesis, to a function from sets to propositions. The failure of fit between the semantics which I have proposed for unembedded descriptions, and how these are understood, might be thought a problem. But, happily, pragmatics can bridge the gap. That, anyway, is what I'll argue.

This isn't the place for laying out the pragmatics of unembedded descriptions in painstaking detail. (Interested readers might look at Stainton (1994), where the interpretation of other non-sentences is discussed at length.) So, I will simply sketch a story about how unembedded descriptions can be used in communication. In order to do so, however, I will need to employ numerous ideas from Relevance Theory (Sperber and Wilson 1987, 1995).

Some definitions. Let logical forms be expressions of mentalese. Let assumptions be propositional logical forms, and assumption schemas be non-propositional logical forms. (In effect, assumptions are sentences of mentalese, while assumption schemas are mentalese predicates, names, quantifier phrases etc.) A logical form is manifest to an individual at a time $t$ only if she is capable of representing it mentally at $t$. But this is not sufficient for manifestness: Roughly, an assumption is manifest at $t$ only if its representor is capable of accepting it as true, or probably true, at $t$; an assumption schema is manifest to its representor at $t$ only if what it represents is perceptible at $t$. Let an individual's assumptionset be the collection of assumptions currently manifest to her. (Assumption-sets cannot, by definition, contain assumption schemas.) Finally, call an assumption $A$ relevant to an individual at a time to the extent that $A$ positively affects the individual's assumption-set. The more positive effects, the more relevant; but also, the less processing cost, (e.g. inferential labour, perceptual effort, memory strain) the more relevant.

Time to put the definitions to work. To fix ideas, I'll focus on one example: I could point at an empty seat and say, 'The head of philosophy'. Assuming this phrase corresponds to a function from sets to propositions, how can it be used communicatively e.g. to remark that the empty seat belongs to the head of philosophy? Here is the general idea. The utterance of the description makes manifest a number of logical forms. In particular, the utterance makes manifest:

(4) (a) The presumption of optimal relevance: that the utterance is relevant enough for it to be worth the addressee's while to process it; and that the utterance is the most relevant one available

(b) The logical form corresponding to the description uttered - in the case at hand, the logical form corresponding to the English expression 'The head of philosophy'. 
(Since I don't know how to write the latter in mentalese, I'll use logical notation: $\left.\lambda g \in\langle e, t\rangle . \lambda w \cdot[\exists ! x \text { head }(x) \& \forall y(\text { head }(y) \supset g(y)=1)]^{w}\right)$

Here is the key claim: Having this much manifest is enough for successful communication, because (4) can serve as a basis for finding the assumption-set consistent with the presumption of optimal relevance - an assumption-set which contains the assumption that the seat belongs to the head of philosophy. And this, as you'll see, is sufficient for communicating the latter assumption.

The assumption-set, at the outset, does not contain (4b) because, though it is a logical form, it is not an assumption. (Remember: Assumptions are, by definition, propositional logical forms; (4b) is non-propositional: It corresponds to a generalized quantifier, not a proposition.) However, the assumption-set can, with very little effort, be made to contain an assumption got from (4b). This is easy enough, assuming some sets/properties are salient: If a set/property $s$ is salient in the environment, then the logical form corresponding to $s$ will be manifest; and a logical form which represents a set, when combined with (4b), yields an assumption. (Compare: A quantifier phrase, when combined with a predicate, yields a sentence.) For instance, combining the logical form will-sit with (4b) gives (5a), which in turn converts to $(5 \mathrm{~b})$ :

(5) (a) $\lambda g \in<e, t>. \lambda w .[\exists ! x \operatorname{head}(x) \& \forall y(\operatorname{head}(y) \supset g(y)=1)]^{w}($ will-sit)

(b) $\lambda w \cdot\left[\exists ! x\right.$ head $(x) \& \forall y(\text { head }(y) \supset \text { will-sit }(y)]^{w}$

Assumption (5b), whose meaning is the proposition that the head of philosophy will sit at the designated location, will be relevant enough in certain circumstances: For instance, it will be relevant enough in a situation in which the interlocutor is looking for a place to sit. Hence an assumption-set containing (5b) satisfies the first part of the presumption of optimal relevance. But - and this is crucial - will-sit will be very manifest in a subset of these circumstances. ${ }^{6}$ Indeed, in some cases where $(5 \mathrm{~b})$ is relevant, will-sit will be the most manifest logical form, beyond (4) itself. In such circumstances, the assumption-set containing (5b) will be the most accessible assumption-set: the first one the hearer considers in her interpretive task. And, as Sperber and Wilson $(1987,1995)$ argue, the most accessible assumption-set which is relevant is the only assumption-set consistent with the presumption of optimal relevance; in turn, the only assumption-set consistent with the presumption of optimal relevance is the assumption-set communicated by the speaker. This set includes (5b). And thus you see how an utterance of 'The head of philosophy' succeeds in communicating a proposition. Presto. Except for one worry.

It might seem that an utterance of 'The head of philosophy' cannot really succeed in communicating a proposition because it will never be the most relevant utterance available. Surely, one might say, a fully sentential utterance will always be more relevant, since spelling everything out for the hearer would require less inferential work (hence less processing effort) on her part. The point is well taken. ${ }^{7}$ But, it is far from clear that supplying more linguistic material must make an utterance easier to process. Quite the 
contrary: Where an appropriate assumption schema is already very manifest (as will-sit is assumed to be in the example above), forcing the hearer to decode a predicate (e.g. [r. will sit there]), and then develop the predicate - only to arrive at an (already partially manifest) logical form - would involve more effort than simply decoding the non-sentence, and conjoining it with the manifest assumption schema. Put more flat-footedly: Sometimes it's more efficient to leave the already-obvious unsaid.

What's more, the use of a bare description might have stylistic effects which make the recovered assumption-set richer than it would otherwise be. Such a use might indicate urgency, or informality, etc. Given this, though it remains an open empirical question, I think it's fair to say that an utterance of an unembedded definite description could well be the most relevant utterance available - given the right circumstances.

Time to sum up. There are familiar reasons for thinking that Russell was right to treat definite descriptions quantificationally; but, because descriptions can be used on their own, outside any sentence, the Russellian sentence-based treatment of descriptions is inadequate from the point of view of interpersonal communication. What's wanted instead is a variation on Russell's theme, but using generalized quantifiers. I have attempted to render the latter pragmatically plausible, by using Relevance Theory to show that assigning this kind of meaning to descriptions is consistent with the fact that bare definite descriptions are used and understood in isolation.

\section{Notes}

1. This paper was written while I was a visiting scholar at UMass-Amherst. Many thanks to my hosts there. In particular, Barbara Partee was instrumental in making my stay at UMass possible. I am grateful to her both on that front, and for very useful suggestions on an earlier draft. In addition, l'd like to thank the participants in the two seminars (one at Smith College, the other at McGill) at which a draft of the paper was presented. Thanks also to Joseph Macdonald, Stephen Neale and Stephen Talmage for comments. And to Edmund Gettier for pressing my thoughts in this area. Funding for this research was provided by the Social Sciences and Humanities Research Council of Canada.

2. There are untold subtleties to the debate between direct reference theorists and senseinclined theorists: issues about what, exactly, Frege's view comes to (see, for example, Dummett 1978); issues about how Fregeans might respond to arguments in favour of direct reference (e.g. Donnellan 1966, Kaplan 1977, Kripke 1972, and Putnam 1973); and so on. But, at least for the moment, I want to leave such subtleties to one side, and simply work within the direct reference tradition.

3. Russell goes still further, and says that natural language proper names aren't terms either! His rationale derives from his notorious principle of acquaintance, together with his atomism. Since this isn't an exegetical paper, I will ignore this complication, and treat natural language names as directly referential.

4. The approach has other virtues as well, some of them noted already by Russell (1905, 1919). Here are two. First, treating descriptions quantificationally allows one to straightforwardly account for the non-substitutivity of descriptions in modal and other intensional 
contexts without introducing intensions for descriptions. Second, Russell's account offers a natural explanation of the ambiguity of (i) - since, because of scope of negation, (i) corresponds to both (ii) and (iii):

(i) The king of France is not bald

(ii) There is exactly one king of France and every king of France is not bald

(iii) It is not the case that there is exactly one king of France and every king of France is bald For further discussion of the merits of Russell's view, see Neale 1990.

5. In case imaginary examples worry you, take a cursory glance at a speech corpus. You'll see that descriptions are very frequently used and understood in isolation. Also, non-sentential expressions of many kinds can be used to perform speech acts: Noun Phrases, Verb Phrases, Prepositional Phrases, etc. Indeed, Barton 1990 argues that any $\mathrm{X}^{\max }$ can be used on its own. See Stainton (1994, 1995, 1997a, b, forthcoming) for examples, and discussion.

6 . To say that will-sit is manifest seems to suggest that the set of things $\{x: x$ will sit at the designated location $\}$ is perceptually salient. This may sound odd to some ears. Frankly, it sounds odd to mine. However, I believe the oddness derives not from supposition that will-sit can be manifest, but rather from an overly simple notion of what this assumption schema might represent. Since what is crucial for my purposes is that will-sit should be manifest, I will simply abstract away from this issue.

7. Thanks to Dan Sperber for drawing my attention to this problem.

\section{Works cited}

Barton, Ellen. Nonsentential Constituents. Philadelphia: John Benjamins Publishing Company, 1990.

Donnellan, Keith. "Reference and Definite Descriptions." Philosophical Review 75 (1966): 281-304

Dummett, Michael. "Frege's Distinction between Sense and Reference." Truth and other enigmas. Cambridge, MA: Harvard University Press, 1978. 116-144.

Kaplan, David. "Demonstratives." Themes from Kaplan. Ed. J. Almog, J. Perry, and H. Wettstein. New York: Oxford University Press, 1989. 481-654.

Kripke, Saul. Naming and Necessity. Cambridge, MA: Harvard University Press, 1972.

Neale, Stephen. Descriptions, Cambridge, MA: The MIT Press, 1990.

Putnam, Hilary. "Meaning and Reference." Journal of Philosophy 70 (1973): 699-711.

Russell, Bertrand. Introduction to Mathematical Philosophy. London, George Allen \& Unwin, 1919.

. "Knowledge by Acquaintance and Knowledge by Description." Proceedings of the Aristotelian Society 11 (1911): 108-128.

. On Denoting, Mind 14 (1905): 479-493.

Sainsbury, R.M. Russell. London: Routledge and Kegan Paul, 1979.

Salmon, Nathan and Scott Soames. Propositions and Attitudes. Oxford: Oxford University Press, 1988.

Sperber, Dan and Deirdre Wilson. Relevance: Communication and Cognition, second edition. Oxford: Blackwell, 1995.

. "Précis of Relevance." The Behavioral and Brain Sciences 10 (1987): 697-710. 
Stainton, Robert J. Quantifier Phrases, Meaningfulness 'in isolation' and Ellipsis." Forthcoming in Linguistics and Philosophy. . "Utterance Meaning and Syntactic Ellipsis." Pragmatics \& Cognition 5 (1997a): 49-76.

."What Assertion Is Not." Philosophical Studies 85 (1997b): 57-73.

. "Non-Sentential Assertions and Semantic Ellipsis." Linguistics \& Philosophy 18 (1995): 281-296.

"Using non-sentences: An application of Relevance Theory." Pragmatics \& Cognition 2 (1994): 269-284. 